\title{
Larval fish in troubled waters - is the behavioural response of larval fish to hydrodynamic impacts active or passive?
}

\author{
Stefan Stoll and Peter Beeck
}

\begin{abstract}
In a mesocosm experiment, we tested whether larval fish show an active behavioural response to hydrodynamic impacts. Exposing 1 to 3 week old allis shad (Alosa alosa) larvae to a pulsed wave regime, we found that already 1 week old larvae immediately adapt their microhabitat use and activity patterns at the onset of the wave pulses. The fish larvae in stantaneously increased their activity level and moved downwards, concentrating in the calmer lower third of the water col umn. Within 4 min after the end of the wave pulse, the fish returned to their former distribution. Two and 3 week old fish larvae foraged close to the bottom substratum during calm periods but avoided this zone during the wave pulses. Thus, larval fish show an active response to hydrodynamic impacts. With the ability to adjust microhabitat use and activity level, already fish larvae are able to trade costs and benefits associated with spatio temporal hydrodynamic heterogeneity. In par ticular, fish larvae should be able to minimize some of the harmful effects of navigation induced waves where calmer eva sion habitats are available.
\end{abstract}

Résumé : Dans le cadre d'une expérience en mésocosme, nous avons évalué si des larves de poisson montrent une réponse comportementale active à des impacts hydrodynamiques. Des larves d'alose (Alosa alosa) âgées d'une à trois semaines ont été exposées à un régime de vagues pulsées. Nous avons observé que les larves d'une semaine adaptent immédiatement leurs patrons d'utilisation de l'habitat et d'activité dès le début des pulsations. Les larves ont ainsi augmenté instantanément leur niveau d'activité et se sont déplacées vers le bas, s'agglomérant dans le tiers le plus calme de la colonne d'eau. Dans les 4 min suivant la fin des ondes pulsées, les poissons avaient repris leur réparation initiale. Les larves de poisson de deux et trois semaines se nourrissaient près du substrat inférieur durant les périodes calmes, mais évitaient cette zone durant les pulsations. Les larves de poisson réagissent donc activement à des impacts hydrodynamiques. Cette capacité d'ajuster leur utilisation de microhabitats et leur niveau d'activité leur permet déjà de trouver un compromis entre les coûts et avantages associés à une hétérogénéité hydrodynamique spatiotemporelle. Plus particulièrement, les larves de poisson devraient être en mesure de minimiser certains des effets néfastes des vagues induites par la navigation là où des habitats d'évasion plus cal mes sont disponibles.

[Traduit par la Rédaction]

\section{Introduction}

The larval and early juvenile life stages of fish are especially affected by hydrodynamic impacts, as at these developmental stages fishes have very limited swimming capacities and are least able to resist flow (Wolter and Arlinghaus 2003). Hydrodynamic impacts are known to affect feeding rates of larval fish by altering their prey encounter rates and prey capture success (MacKenzie and Kiørboe 1995; MacKenzie et al. 1994; Rothschild and Osborn 1988). Furthermore, hydrodynamic impacts can change the swimming activity of fish larvae (Utne-Palm 2004; Utne-Palm and Stiansen 2002). Also, indirectly, through the resuspension of fine particles causing turbidity, hydrodynamic impacts affect the foraging efficiency of fish larvae (Utne-Palm and Stiansen 2002). Common sources of hydrodynamic impacts in open water habitats are wind and ship traffic (Hofmann et al. 2008). In rivers and canals, current and ship traffic are the predominant source of hydrodynamic impacts (Mazumder et al. 1993).

While many studies describe the various direct and indirect effects of hydrodynamic impacts on the bioenergetics of fish larvae (MacKenzie and Kiørboe 1995; Rothschild and Osborn 1988; Utne-Palm 2004), little is known about the age at which fish are capable to detect gradients of hydrodynamic impacts and actively react to them. However, this knowledge has important implications because the competence to detect

Paper handled by Associate Editor Michael Bradford.

S. Stoll. Biodiversity and Climate Research Centre \& Senckenberg Research Institute and Natural History Museum Frankfurt, Department of River Ecology and Conservation, Clamecystr. 12, 63571 Gelnhausen, Germany; Limnological Institute, University of Konstanz, 78457 Konstanz, Germany.

P. Beeck. Stiftung Wasserlauf, Geschäftsstelle EU Life Projekt Maifisch, Aquazoo Löbbecke Museum, Kaiserswerther Straße 380, 40200 Düsseldorf, Germany.

Corresponding author: Stefan Stoll (e mail: stefan.stoll@senckenberg.de). 
and orient along hydrodynamic gradients enables fish to trade the costs and benefits associated with different levels of hydrodynamic impacts.

In previous studies on the effects of waves on larval fish, the larvae have mainly been considered passive elements upon which the hydrodynamic impacts act. For example, studies that investigated changes in larval fish distribution before and after the passage of vessels discuss those changes in the context of a passive translocation of fish larvae caused by currents induced by the vessels (Holland 1986; Holland and Sylvester 1983; Kucera-Hirzinger et al. 2009). This view may have been guided by the fact that the lateral line system that fish use to sense hydrodynamic cues is not fully developed in freshly hatched fish larvae. The number of neuromasts increases greatly during the postembryonic growth (Sapède et al. 2002). Also, the brains of fish larvae, particularly the eminentia granularis and crista cerebellaris where stimuli of the lateral line are processed, are often not yet fully differentiated. The differentiation process continues up to the postlarval stages (Montgomery and Sutherland 1997).

However, changing macro- and mesohabitat scale distribution patterns of larval and early juvenile fish in relation to wave exposure suggest that larval and early juvenile fish already show some active behavioural reactions to hydrodynamic impacts (Lienesch and Matthews 2000; Stoll et al. 2010a; Watt-Pringle and Strydom 2003).

Later life stages of fish, in contrast, are known to be capable of detecting hydrodynamic impacts. These fish frequent different shore habitats in lakes according to the wind direction and subsequent wave action (Lienesch and Matthews 2000). Furthermore, some species consider the wave exposure when selecting their spawning site (Probst et al. 2009) because egg survival can be affected by wave exposure in shallow water-spawning fish (Holland 1987; Rupp 1965; Stoll et al. 2010b).

This study examines the minimum age from which fish can detect hydrodynamic gradients using the case of navigation-induced hydrodynamic impacts in the littoral zones of large rivers, canals, or lakes. For many fish species, these littoral areas with low discharge-related flow are important nursing areas (Copp 1992; Lamouroux et al. 1999; Scheidegger and Bain 1995). At the same time, this is the zone where navigation-induced hydrodynamic impacts are most pronounced (Mazumder et al. 1993). Since shipping is considered an eco-friendly transport mode in terms of energy efficiency, ship traffic in both rivers and canals is predicted to increase further (European Commission 2006). Nevertheless, the ecological impacts resulting from fostering inland navigation are widely unknown.

Besides the bioenergetic effects, navigation-induced waves and splash can cause stranding in fish larvae (Stoll and Beeck 2011) or dislocate them from their preferred habitats (Kucera-Hirzinger et al. 2009). Especially during the night, when many larval and early juvenile fish are inactive, water movement resulting from ship navigation determines their drift (Gaudin 2001; Holland and Sylvester 1983). If water velocities during ship passages exceed the maximum swimming speed of fish, navigation can even completely exclude fish from a habitat. This effect is described as navigation-induced habitat bottleneck (Arlinghaus et al. 2002; Wolter and Arlinghaus 2003).
Since inshore habitats in navigational waterways are commonly characterized by steep spatio-temporal gradients of hydrodynamic impacts, evasive manoeuvres to reduce the exposure to hydrodynamic impacts would commonly be feasible on relatively small spatial scales. If already larval fish were able to detect gradients of hydrodynamic impact and orient themselves along them, this would help them to avoid physically harmful levels of hydrodynamic impacts and even profit from increased foraging success at intermediate levels of hydrodynamic impact (MacKenzie et al. 1994). Studying the reaction of fish larvae to surface wave pulses that mimicked ship traffic, we investigated whether (and from which age) fish larvae actively react to hydrodynamic impacts. To this end, two reaction variables were measured: the residence time in different microhabitats and swimming activity.

\section{Materials and methods}

\section{Allis shad}

This study was performed with allis shad (Alosa alosa) larvae that were provided by MIGADO (Association pour la restauration et la gestion des poissons migrateurs du basin de la Garonne et de la Dordogne). The yolk sac larvae were transported to the Limnological Institute of the University of Konstanz where the experiments took place. The fish were stored in round $20 \mathrm{~L}$ holding tanks with a gentle circular current. The water temperature was maintained at $20{ }^{\circ} \mathrm{C}$. The fish were fed with artemia and a commercial powder food for fish larvae. Three age classes of fish larvae were tested in the experiments: 1-week-old fish larvae (8 12 days) with a mean total length of $11.6 \pm 1.3 \mathrm{~mm}$ (mean \pm standard deviation, SD), 2-week-old fish larvae (15 20 days) with a total length of $13.5 \pm 1.8 \mathrm{~mm}$, and 3-week-old fish larvae (21 27 days) with a total length of $15.5 \pm 1.9 \mathrm{~mm}$.

\section{Experimental setup and procedures}

The experiments were conducted in a wave mesocosm at the Limnological Institute of the University of Konstanz. This mesocosm had a base dimension of $10 \mathrm{~m} \times 1 \mathrm{~m}$ and a water depth of $0.84 \mathrm{~m}$ (Fig. 1a). One side of the mesocosm was a glass wall that allowed for direct observation of the fish throughout the experiments. A slope was installed at one end to simulate a littoral zone. The slope was constructed using a metal grid that was covered by a thick canvas and topped with a $1015 \mathrm{~cm}$ deep layer of gravel and stones. The grain sizes used $(12 \mathrm{~cm}$ and $620 \mathrm{~cm})$ are representative of the natural substrata that dominate in many eulittoral areas of large rivers and canals, such as the river Rhine (Frings et al. 2008).

A wave machine was situated on the opposite side of the mesocosm. The waves were generated in pulses of $1 \mathrm{~min}$ followed by $4 \mathrm{~min}$ of wave pause. This frequency of 12 wave pulses per hour imitated the average number of ship passages on the Rhine, which is 11.3 ships per hour averaged from the number of ship passages from the Upper, Middle, and Lower Rhine (P. Beeck, personal observation). The experimental setup delivered near-harmonic waves with a maximum wave height of $0.13 \mathrm{~m}$, a wave period of $1.2 \mathrm{~s}$, and a wave number of $2.8 \mathrm{~m}^{-1}$ at the bottom of the slope and $3.1 \mathrm{~m}^{-1}$ near the surf zone. The current velocities induced by the waves were measured with an Acoustic-Doppler Velocimeter (ADV; 
Fig. 1. Design of the mesocosm (a). The different compartments are named c0 c7. A, wave generator; B, water inlet; C, water outlet; T1 T4, position of the temperature loggers. The range of maximum orbital current velocities $\left(u_{\max }\right)$ per compartment $(b)$. In the splash zone and close to the bottom ( $\mathrm{c} 0$ and $\mathrm{c} 7$ ), no measurements could be made.

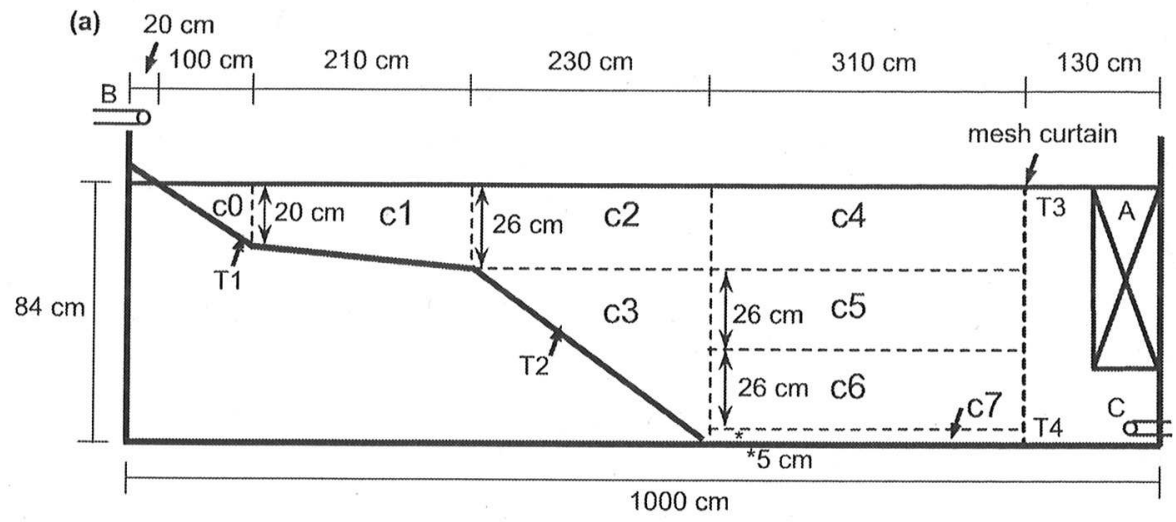

(b)

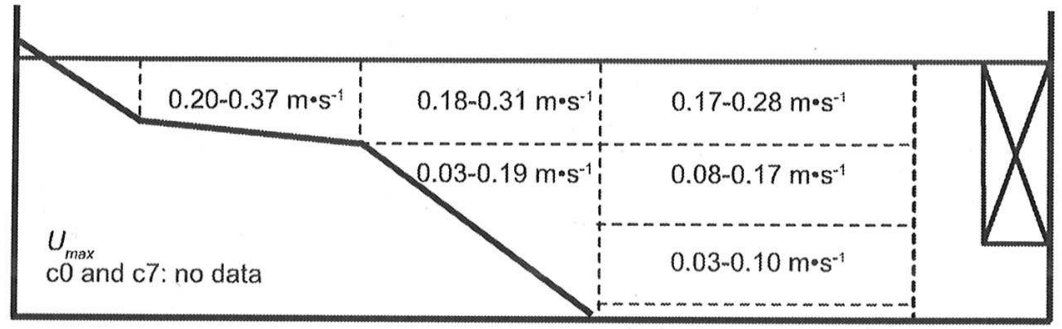

NORTEK, Boston, Mass., USA). A minimum of five point measures per compartment, each lasting for $1 \mathrm{~min}$, were taken during permanent wave action. Maximum orbital current velocities $u_{\max }$ were calculated using linear wave theory (Kundu and Cohen 2002). In compartments $\mathrm{c} 0$ and $\mathrm{c} 7$, the ADV could not be used because of the dimensions of the $\mathrm{ADV}$ and its stand. For the same reason, no measurements closer than $5 \mathrm{~cm}$ to the side walls could be made. Outside this threshold distance, no edge effects along the side wall with reduced $u_{\max }$ were detected. Within $1 \mathrm{~min}$ after the termination of a wave pulse, $u_{\max }$ decreased to $00.03 \mathrm{~m} \cdot \mathrm{s}^{-1}$ in all compartments. Because of the limited dimensions of the mesocosm, the waves that were generated were shorter than typical waves produced by ships (Stoll and Fischer 2011).

Measurements of $u_{\max }$ ranged between $0.03 \mathrm{~m} \cdot \mathrm{s}^{-1}$ in compartments $\mathrm{c} 3$ and $\mathrm{c} 6$ to $0.37 \mathrm{~m} \cdot \mathrm{s}^{-1}$ in compartment $\mathrm{c} 1$ (Fig. 1b). Two gradients of $u_{\max }$ were present. First a vertical gradient with higher values close to the water surface, and second, a bank offshore gradient with an inverse relationship between $u_{\max }$ and water depth. Hence, the current velocities of these waves were at the lower end of the velocity spectrum of the waves that are induced by ships, which typically reach up to $0.71 .0 \mathrm{~m} \cdot \mathrm{s}^{-1}$ in the straight reaches of shipping canals (Wolter et al. 2004).

The area closest to the wave machine was separated from the rest of the mesocosm by a frame strung with a $4 \mathrm{~mm}$ knot-to-knot mesh to prevent the fish from being crushed by the paddle of the wave machine. The mesh of this size was not an impermeable physical barrier for the small and slender fish. Therefore, the mesh barrier was continuously monitored throughout the experiments through the glass wall on the one side of the mesocosm to determine if fish larvae were penetrating the mesh. However, the vast majority of the fish lar- vae accepted the mesh as a barrier and only a few 1-weekold fish larvae $(<2 \%)$ passed it. The fish that passed the mesh barrier were immediately removed from the wave machine compartment using a dip net and were transferred back to the other side of the barrier.

The water temperature was measured throughout the experiment using Onset temperature loggers (Onset, Bourne, Mass., USA) at four locations in the mesocosm with a resolution of $12 \mathrm{~h}^{-1}$ (Fig. 1a). The water temperatures measured throughout the experiments ranged between 15.5 and $26.2^{\circ} \mathrm{C}$ throughout the study period. The waves prevented the establishment of a pronounced vertical temperature gradient in the water column. On average, the temperature difference between the warmest and the coldest part of the mesocosm was only $0.2^{\circ} \mathrm{C}$.

The mesocosm was fed with water from Lake Constance using a flow-through system with a complete water exchange every $24 \mathrm{~h}$. The water was introduced into the mesocosm on the slope side and drained via an outlet situated at the opposite end of the mesocosm near the wave machine.

One experiment using 100 fish larvae was run per day. Thus, with three age classes and eight replicate experiments per age class, a total of 24 full day experiments were run. To transfer the fish larvae from the holding tanks to the wave mesocosm, the fish larvae were scooped out of the holding tank using a $1 \mathrm{~L}$ beaker and gathered in a $10 \mathrm{~L}$ bucket where the water temperature was matched to the water temperature in the wave mesocosm over a period of $1 \mathrm{~h}$. At 09:30, the fish larvae were introduced into the mesocosm. After an acclimatisation period of $30 \mathrm{~min}$, the fish larvae were exposed to the wave scenario from 10:00 to 17:15. The behaviour of the fish was recorded hourly during observation periods of $15 \mathrm{~min}$. Thus, each observation period contained 
three wave pause cycles of 5 min each, starting with a wave pulse. For the behavioural records, one focal fish was chosen for each observation period. With 100 individuals present, the probability that the same fish was observed twice was low. To ensure an unbiased selection of the compartment in which the observation started, the fish that was the closest to the glass wall at the moment when the experiment started was always chosen. During each observation, two variables of the focal fish were assessed: (i) The fish's residence time in different microhabitats of the mesocosm was recorded using the Perchmon program (Borcherding and Magnhagen 2008). To this end, the mesocosm was divided into eight compartments that were named sequentially c0 c7 (Fig. 1). The borders between the compartments were drawn with a permanent marker on the glass wall. (ii) The swimming activity was measured. For this purpose, a grid of squares with side lengths of $20 \mathrm{~cm}$ was drawn on the glass wall, and the line crossings of the focal fish were counted for each minute interval during the observation period. During the first four replicate days of 1-week-old fish larvae and the first three replicates of 2-week-old fish larvae, no swimming activity measures were taken yet.

Additionally, during each observation, the weather condition was noted. The conditions were categorized as sunny (direct sunshine), cloudy (less than two thirds of the sky was covered with clouds and the sun was hidden), overcast (more than two thirds of the sky was covered with clouds and the sun was hidden), and rainy weather. The four different weather conditions occurred with similar frequencies in the experiments performed with 1- and 3-week-old fish; the expected proportion of each weather condition was $25 \%$, and the realised proportions were $18 \% 35 \%$. As the only exception, in the experiments with 2-week-old fish, sunny weather prevailed during $60 \%$ of the measurements, and no rainy weather occurred.

At the end of the experiment, the fish larvae were caught again with a dip net and transferred back to the laboratory. Each fish larva was only used one time for the experiments.

\section{Data analyses and statistics}

Throughout the observation period of the three wave pause cycles, the average durations of stay of the fish larvae in the different compartments during the minute of wave pulse and the individual minutes (1 4) of the wave pause were calculated. To stabilize the variance, these data were $\log (x+1)$-transformed. To examine the compartment use patterns of the fish larvae, general linear models (GLM) were used, with time intervals spent at the different compartments as dependent variable. The principal independent variables of interest were compartment identity and wave cycle; time of day, temperature, and weather were used as control variables. To account for the repeated measurement structure of the data, also the term day was added to the set of independent variables. To reveal the effects of the wave cycle, temperature, weather, time of day, and day on the compartment use of the larval fish, the statistical model contained all second degree interactions of the term compartment identity. Significant interactions were further examined using Student's post-hoc tests, in case of continuous independent variables, linear regressions. To test upwards and downwards movements at the onset of the wave pulses, contrast analyses were applied. Only compartments that were frequented at least $10 \%$ of the total time budget could be considered in the analysis, since otherwise the high proportion of zero-values impaired the homoscedasticity of the data. Each of the three age groups of the fish larvae was analysed separately.

Also the swimming activity patterns of the fish larvae were analysed with a GLM. The averaged numbers of line crossings per minute over the three wave cycles per observation period were analysed, using the independent variables wave cycle, time of day, temperature, weather, and day. A one-way analysis of variance (ANOVA) was used to compare the swimming activity of the fish between age groups.

All of the statistical tests were performed using JMP software (SAS Institute Inc., Cary, N.C., USA) and the R program ( $R$ Development Core Team, Vienna, Austria). The normal distribution of the data was tested with KolmogoroffSmirnov tests and the homoscedasticity was tested with Bartlett tests.

\section{Results}

\section{Behavioural reaction of the fish larvae to waves}

Throughout all of the experiment's replicate runs, the fish larvae never formed schools in terms of two or more fish grouping together and orienting in a common direction. Occasionally, the 2- and 3-week-old fish clustered loosely, staying in groups of up to 20 individuals at distances of about 10 body lengths from each other but without orientating their body axes into the same direction. These clusters broke up again after approximately $3060 \mathrm{~s}$.

\section{Residence time in microhabitats}

The microhabitat choice of the fish larvae depended on a complex interaction of the phases of the wave pause cycle, the water temperature, the weather conditions, the time of day, and the day. Further, their microhabitat preferences and the variables that affected these preferences partly shifted during their first three weeks of life (Table 1). As a general pattern, all of the age classes of fish larvae avoided the shallow inshore compartments $\mathrm{c} 0, \mathrm{c} 1$, and $\mathrm{c} 2$ and preferred the open water compartments c5 and c6 (Fig. 2). Furthermore, in all three age classes a significant interaction between compartment and wave cycle indicated a shift in microhabitat preference in relation to waves. The 1-week-old fish larvae used the slope and open water compartments $\mathrm{c} 3, \mathrm{c} 4, \mathrm{c} 5$, and c6 for at least $10 \%$ of their time in some of the phases of the wave pause cycle (Figs. $2 a 2 e$ ). With the onset of a wave pulse, an instant shift downwards in the water column from compartment $\mathrm{c} 4$ to the calmer $\mathrm{c} 6$ was recorded. Throughout the $4 \mathrm{~min}$ of the pause between the wave pulses, the fish larvae moved upwards in the water column, increasing the use of compartments $\mathrm{c} 4$ and $\mathrm{c} 5$.

The 2-week-old fish larvae significantly preferred compartment c6 to all of the other compartments (Figs. $2 f 2 j$ ). Throughout the $4 \mathrm{~min}$ of the pause between the wave pulses, these fish larvae also used compartments $\mathrm{c} 5$ and $\mathrm{c} 7$ in increasing proportions; however, with the onset of each new wave pulse, they immediately moved back to compartment c6.

For the 3-week-old fish larvae, the compartment use was even more restricted to c6 with $71 \% 83 \%$ of the total time 
Table 1. Results of the GLM analysing residence time of 1,2, and 3 week old fish larvae in the different compartments.

\begin{tabular}{|c|c|c|c|c|c|c|c|c|c|c|c|c|}
\hline \multirow[b]{3}{*}{ Factor } & \multicolumn{4}{|c|}{1 week old } & \multicolumn{4}{|c|}{2 week old } & \multicolumn{4}{|c|}{3 week old } \\
\hline & \multicolumn{4}{|c|}{$R^{2}=0.39$} & \multicolumn{4}{|c|}{$R^{2}=0.42$} & \multicolumn{4}{|c|}{$R^{2}=0.58$} \\
\hline & df & $\mathrm{SS}$ & $F$ & $p$ & df & SS & $F$ & $p$ & $\mathrm{df}$ & SS & $F$ & $p$ \\
\hline Time of day & 1 & 2.2 & 4.4 & 0.036 & 1 & 0.4 & 0.8 & 0.369 & 1 & 0.1 & 0.2 & 0.620 \\
\hline Temperature & 1 & 0.2 & 0.5 & 0.498 & 1 & 0.5 & 1.0 & 0.309 & 1 & 0.3 & 0.7 & 0.401 \\
\hline Weather & 3 & 2.7 & 1.8 & 0.150 & 2 & 4.0 & 4.1 & 0.018 & 3 & 0.6 & 0.6 & 0.643 \\
\hline Day & 7 & 2.6 & 0.7 & 0.641 & 7 & 5.8 & 1.7 & 0.111 & 7 & 2.8 & 1.1 & 0.357 \\
\hline Wave cycle & 4 & 3.6 & 1.8 & 0.126 & 4 & 3.5 & 1.8 & 0.130 & 4 & 2.5 & 1.7 & 0.149 \\
\hline Compartment & 3 & 108 & 71.9 & $<0.001$ & 3 & 163 & 110 & $<0.001$ & 3 & 292 & 268 & $<0.001$ \\
\hline Compartment $\times$ Time of day & 3 & 2.9 & 1.9 & 0.126 & 3 & 1.2 & 0.8 & 0.480 & 3 & 7.6 & 7.0 & $<0.001$ \\
\hline Compartment $\times$ Temperature & 3 & 5.7 & 3.8 & 0.010 & 3 & 1.3 & 0.9 & 0.459 & 3 & 6.9 & 6.3 & $<0.001$ \\
\hline Compartment $\times$ Weather & 9 & 21.3 & 4.7 & $<0.001$ & 6 & 13.1 & 4.4 & $<0.001$ & 9 & 7.1 & 2.2 & 0.021 \\
\hline Compartment $\times$ Day & 21 & 46.4 & 4.4 & $<0.001$ & 21 & 34.1 & 3.3 & $<0.001$ & 21 & 40.9 & 5.4 & $<0.001$ \\
\hline Compartment $\times$ Wave cycle & 12 & 11.9 & 2.0 & 0.022 & 12 & 12.7 & 2.1 & 0.013 & 12 & 8.1 & 1.9 & 0.036 \\
\hline
\end{tabular}

Note: Significant results are presented in bold.

spent in this compartment (Figs. $2 k 2 o$ ). Throughout the wave pause cycle, significant changes in the compartment use occurred in compartment $\mathrm{c} 7$ with an increased use during the 4 min of pause between the wave pulses and an instant shift back to compartment c6 with the onset of the next wave pulse.

In addition to the differences in compartment preference throughout the wave pause cycle, significant interactions between compartment and the time of day, water temperature, weather, and day of the experiment also occurred (Table 1). The time of day influenced compartment use only in 3week-old fish larvae. Linear regression showed that throughout the day, these fish larvae reduced their use of deep water slope compartment $\mathrm{c} 3$ in favour of all of the other compartments; however, with a decrease from an average of $9 \%$ of the total time spent in this compartment at the first observation of the day to $6 \%$ at the last observation of the day, this was not a severe shift. The significant interaction between compartment and temperature in 1-week-old fish larvae was caused by an increased use of deep open water compartment c6 with higher temperatures, while lower temperatures increased the use of the surface open water compartment c4. Also in 3-week-old fish larvae, the use of compartment c6 increased with water temperature. In a weather gradient ranging from sunny to cloudy, overcast and rainy, all age classes increasingly used the deep open water compartment c6 at good weather conditions. In contrast, with deteriorating weather conditions, all fish larvae used the more surface and bank-oriented compartments $\mathrm{c} 3, \mathrm{c} 4$, and $\mathrm{c} 5$ to a greater extent.

In all three age classes, the compartment use varied between the replicate days of the experiment. This interaction was largely driven by the between-day variation in water temperature, since the variable day was highly correlated to temperature $\left(R^{2}=0.89\right)$. During warm days, the deep open water compartment c6 was used to an above-average proportion, while during colder days the more surface-oriented compartments c5 and c4 were increasingly frequented.

The significant value for the variable weather in 2 -weekold fish larvae reflect the unequal proportions of the four weather categories during the experiments using this age class (Table 1). The significant effect of time of day in 1- week-old fish larvae was caused by a slight decrease of the proportion of time spent in the compartments that were included in the analysis (c3, c4, c5, and c6) compared with the compartments that were not $(\mathrm{c} 0, \mathrm{cl}, \mathrm{c} 2$, and $\mathrm{c} 7)$, but with a decrease in total proportion of time spent in included compartments from $93 \%$ at the first observation to $91 \%$ at the last observation, this was not a strong effect.

\section{Swimming activity}

The general level of swimming activity differed between the three age classes of larval fish $\left(F_{[2,637]}=360.2 ; p<\right.$ 0.001 ), from an average of 3 field changes per minute in 1week-old fish to 6 field changes per minute in 2-week-old fish and 8 field changes per minute in 3-week-old fish. The swimming activity level of all of the age groups of fish larvae was highest during the wave pulse and decreased throughout the $4 \mathrm{~min}$ of wave pause (Table 2; Fig. $3 a$ ). In all of the age classes, the swimming activity further decreased with deteriorating weather. This effect was significant in 1- and 3-week-old fish larvae and marginally significant in 2-week-old fish larvae (Table 2; Fig. 3b). A direct relation between swimming activity and temperature was found in 3week-old fish larvae (Table 2; Fig. 3c). In 1-week-old fish larvae, the level of swimming activity decreased throughout the day from an average of 3.0 line crossings per minute at the first observation to 2.5 line crossings per minute at the last observation. Finally, the level of swimming activity differed significantly (2- and 3-week-old fish larvae) or marginally significant (1-week-old fish larvae) between the replicate days. Again, this effect was largely driven by the betweenday variability in temperature. Particularly at warm days, the average swimming activity level was high. Furthermore, age differences within the week classes affected the swimming activity level. In replicates that used fish close to the upper limit of an age class produced above-average swimming activity levels; replicates with fish close to the lower boundary of an age class produced below-average swimming activity levels.

\section{Discussion}

Already in their first week of life, the larval fish were able to detect gradients of wave-generated hydrodynamic impacts 
Fig. 2. Residence time in compartments $\mathrm{c} 0 \mathrm{c} 7(\%$; mean \pm standard deviation, SD) of 1 week old $(a e), 2$ week old $(f j)$, and 3 week old $(k o)$ fish larvae. The five frames for each age class show the compartment use during each of the minutes $\left(\begin{array}{ll}1 & 4\end{array}\right)$ of the pause phase followed by the $1 \mathrm{~min}$ wave pulse. Capital letters indicate significant differences in the compartment use within one frame, and lowercase letters indi cate differences in the use of one compartment between the five frames. Where no lowercase letters are given, no significant differences were found. Only the compartments that were used more than $10 \%$ in at least one frame were included in the statistical analyses. The arrows with an asterisk give the direction of significant migrations between minute four of the pause phase and the wave pulse.
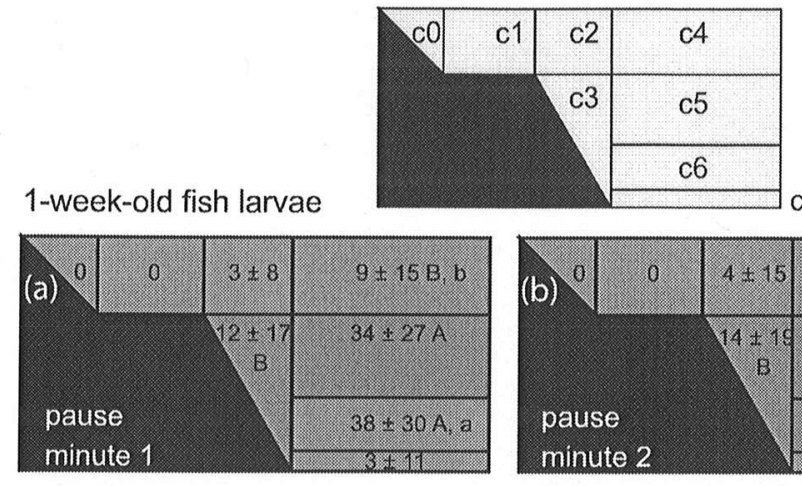

residence time [\%]
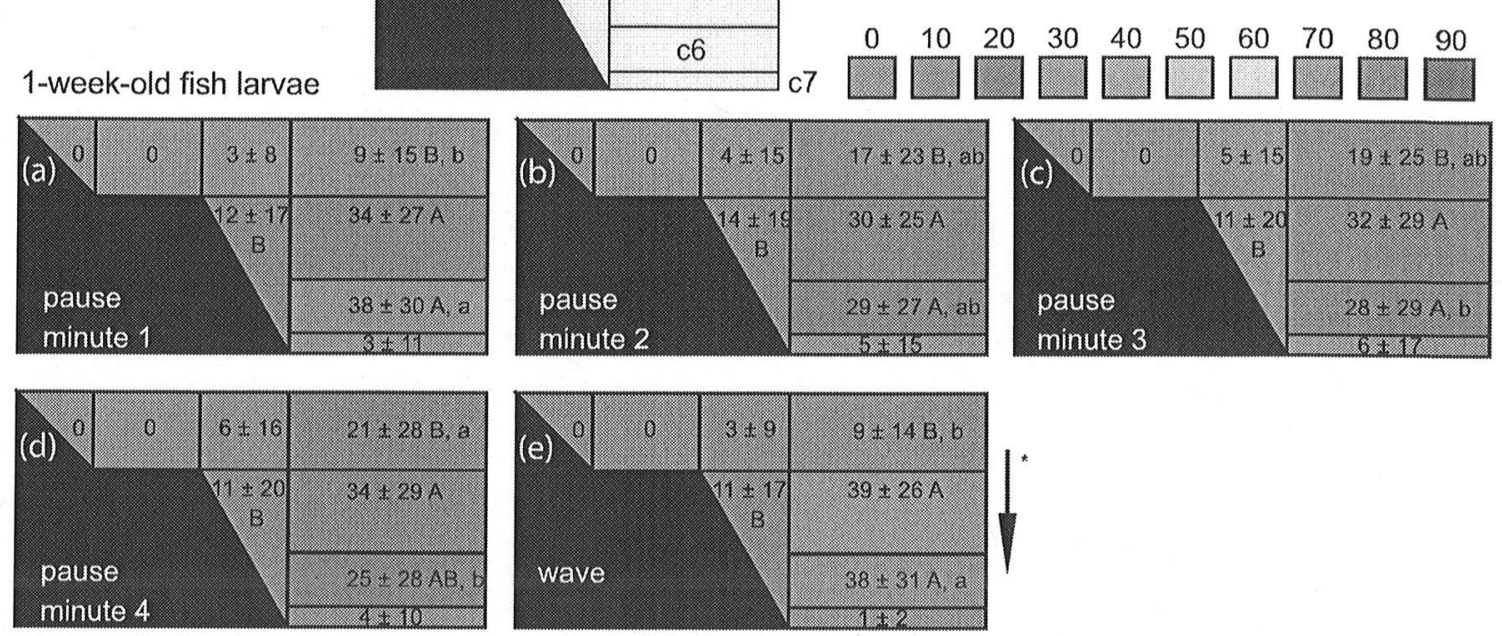

\section{2-week-old fish larvae}
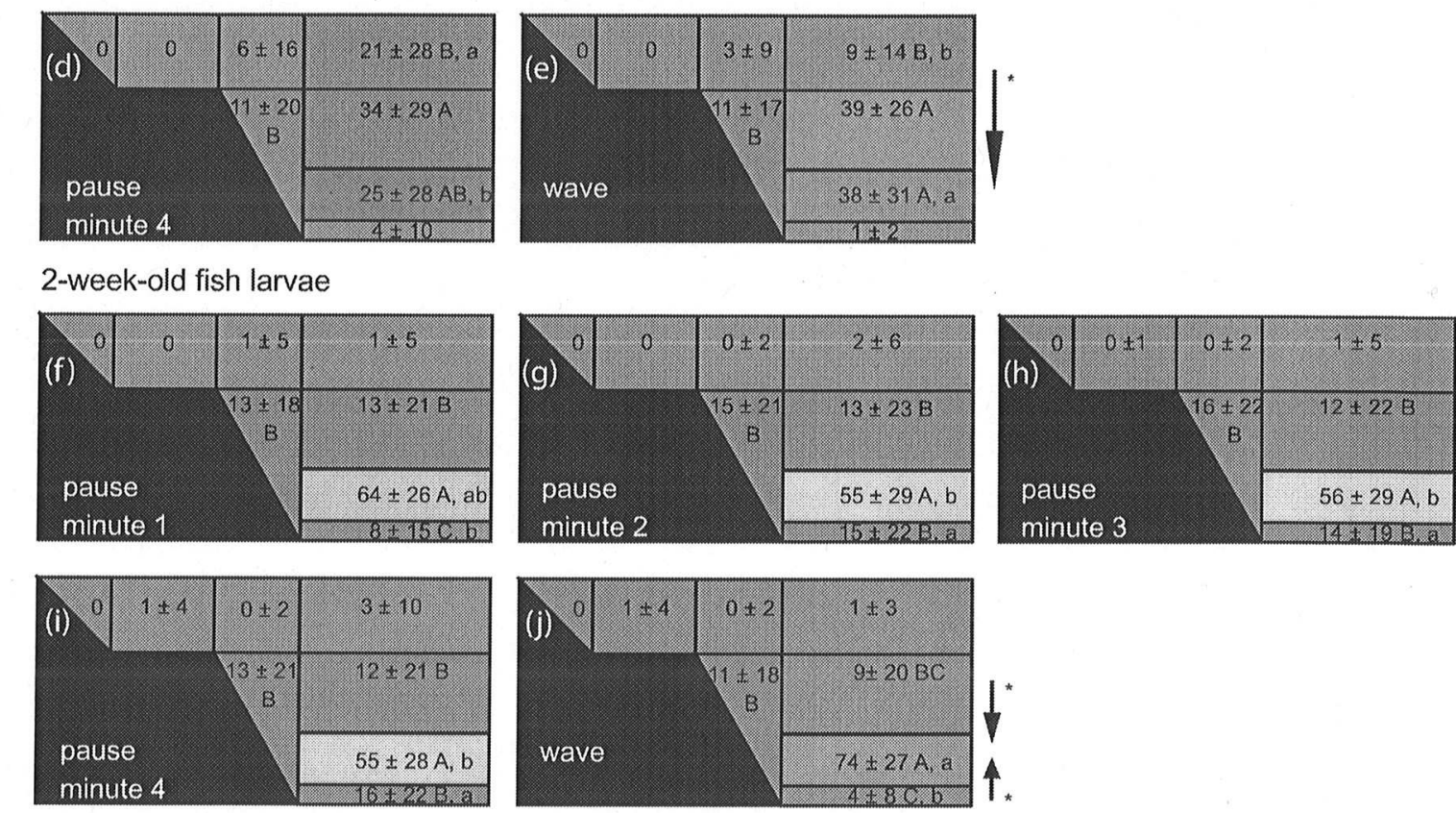

3-week-old fish larvae
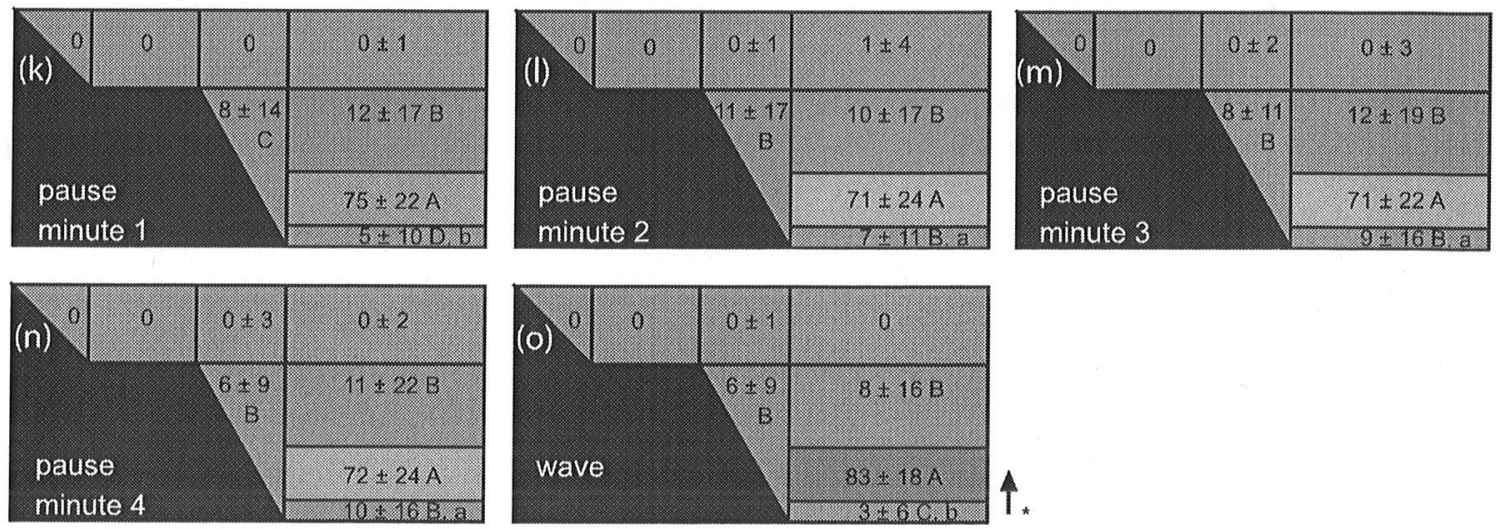
Table 2. Results of the GLM analysing the swimming activity patterns of 1,2, and 3 week old fish larvae.

\begin{tabular}{|c|c|c|c|c|c|c|c|c|c|c|c|c|}
\hline \multirow[b]{3}{*}{ Factor } & \multicolumn{4}{|c|}{1 week old } & \multicolumn{4}{|c|}{2 week old } & \multicolumn{4}{|c|}{3 week old } \\
\hline & \multicolumn{4}{|c|}{$R^{2}=0.61$} & \multicolumn{4}{|c|}{$R^{2}=0.61$} & \multicolumn{4}{|c|}{$R^{2}=0.60$} \\
\hline & $\mathrm{df}$ & SS & $F$ & $p$ & $\mathrm{df}$ & SS & $F$ & $p$ & $\mathrm{df}$ & SS & $F$ & $p$ \\
\hline Wave cycle & 4 & 98.3 & 29.3 & $<0.001$ & 4 & 270 & 25.9 & $<0.001$ & 4 & 258 & 25.7 & $<0.001$ \\
\hline Weather & 3 & 11.7 & 7.0 & 0.001 & 3 & 13.6 & 2.6 & 0.076 & 3 & 141 & 18.8 & $<0.001$ \\
\hline Temperature & 1 & 0.1 & 0.1 & 0.754 & 1 & 2.6 & 1.0 & 0.321 & 1 & 24.5 & 9.8 & 0.002 \\
\hline Time of day & 1 & 4.8 & 5.7 & 0.018 & 1 & 0.0 & 0.0 & 0.944 & 1 & 0.5 & 0.2 & 0.664 \\
\hline Day & 4 & 5.4 & 2.1 & 0.098 & 5 & 350 & 26.8 & $<0.001$ & 7 & 108 & 6.2 & $<0.001$ \\
\hline
\end{tabular}

Fig. 3. Swimming activity of 1 week old (grey), 2 week old (white) and 3 week old (black) fish larvae in relation to the wave cycle $(a)$, weather $(b)$, and water temperature $(c)$. The temperature dependence of swimming activity relates to 3 week old fish larvae $(y=0.89 x$ $\left.10.3 ; R^{2}=0.18 ; p<0.001\right)$. In $(a)$ and $(b)$, the significant differences within age classes are indicated by different letters. Rainy weather did not occur during the experiments with 2 week old fish larvae.

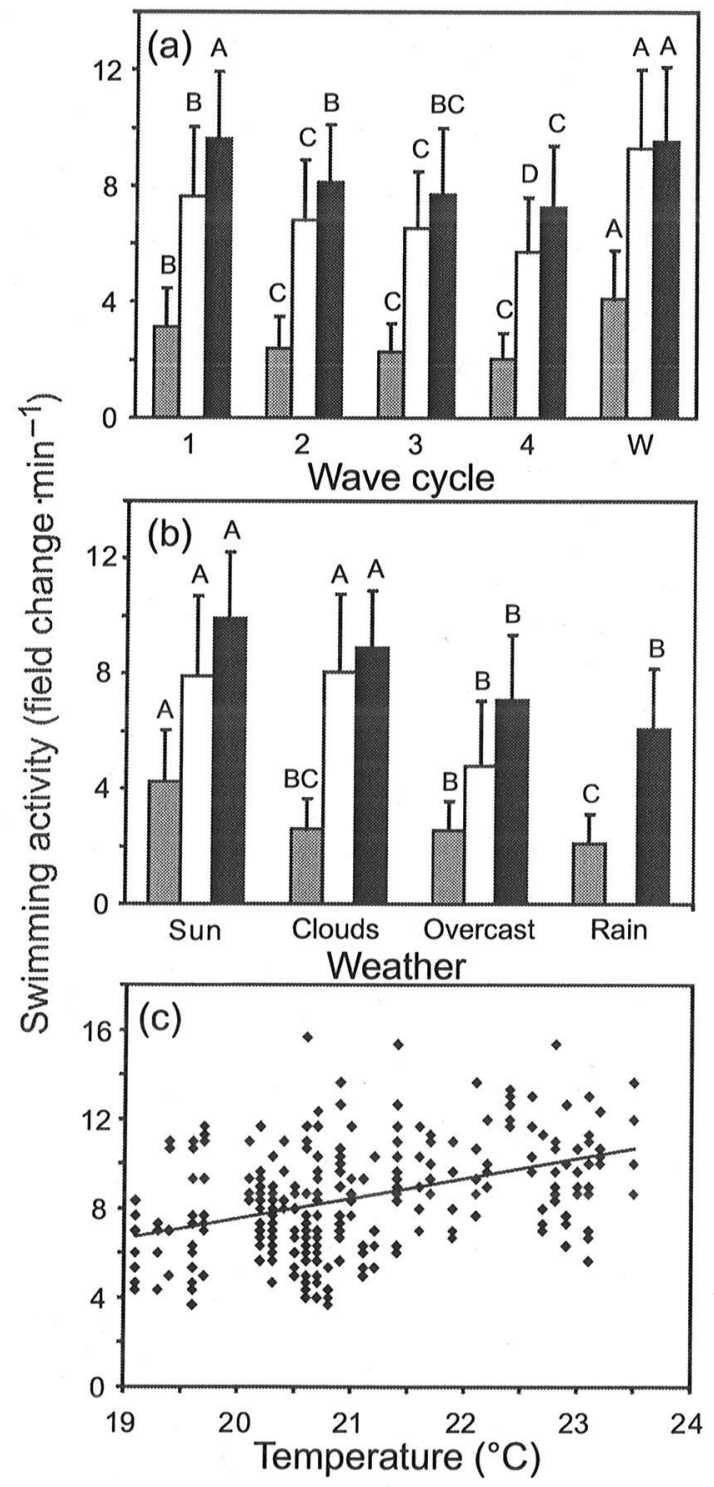

and actively react to them. With the onset of a wave pulse, the fish larvae immediately changed their preferred position in the water column and increased their swimming activity. Such hydrodynamic gradients occur in many different habitat types. Beside hydrodynamic impacts caused by ships traffic, steep vertical hydrodynamic gradients occur also as a result of wind waves in both limnic and marine open waters, since the orbital flow velocity decreases quickly with water depth (Kundu and Cohen 2002).

To our knowledge, this study is the first one describing an active behavioural response in relation to wave pulses and to hydrodynamic impacts in general in such an early life stage of fish. This result is in discordance with the results of Veron et al. (2003), who did not find differences in microhabitat use in experiments performed with larval allis shad in flume tanks. However, the maximum current velocity of $6.4 \mathrm{~cm} \cdot \mathrm{s}^{-1}$ induced in their study was much lower than that used in our study, and the size of their tanks $(2 \mathrm{~m} \times 0.3 \mathrm{~m} \times 0.19 \mathrm{~m})$ may also have made the detection of shifts in microhabitat use difficult.

Throughout the larval ontogeny, both the microhabitat preferences and the behavioural reaction of the fish larvae to waves changed. One- and 2-week-old fish larvae commonly used the surface and midwater zone off the littoral slope to a considerable extent during the wave pauses but immediately moved downwards at the onset of the wave pulses to the lower third of the open water column where the current velocities were lowest in the mesocosm and did not exceed $0.1 \mathrm{~m} \cdot \mathrm{s}^{-1}$. Two- and 3-week-old fish larvae increasingly used the deep open water microhabitat and the zone close to the bottom during the wave pauses; however, they avoided the direct proximity to the rough substratum during the wave pulses, possibly to avoid being trapped and damaged between the stones (Kucera-Hirzinger et al. 2009).

The results of this study indicate that fish larvae should not be considered passive particles whose physiological reactions can be directly derived from the ambient level of hydrodynamic impact. Instead, larval fish can move actively and nonrandomly along hydrodynamic gradients. This ability may allow larval fish to actively reduce some of the most harmful effects of waves by moving to areas where current velocities are benign to them. Thereby, their risk of injury, activity costs, and drift to unsuitable microhabitats can be minimized.

In addition to the microhabitat preferences, also the swimming activity levels of the fish larvae changed throughout the wave pause cycle: An elevated swimming activity in response to waves was also found in juvenile dace (Leuciscus 
leuciscus) and bream (Abramis brama) by Gabel et al. (2011). It was suggested that fish increase their swimming activity in turbulent environments because their posture stability increases with a higher swimming speed (Stoll and Fischer 2011; Webb 2002). Especially in larval fish with a limited scope of activity (sensu Wieser 1985), the energetic costs of locomotion are high. Therefore, the activity costs are crucial to the energetic budget, and the costs and benefits of an increased level of activity have to be carefully balanced (Flore et al. 2001).

The fish larvae also responded to other environmental variables, namely the water temperature and the weather conditions, by changes in their microhabitat choice and swimming activity level. The type of reaction varies between species, ontogenetic stages within species, season, daytime, and other variables (Baltz et al. 1987; Elso and Greenberg 2001). For example, Hurst et al. (2009) showed that similarly to the results of the present study, larval Pacific cod (Gadus macrocephalus) exhibit a stronger surface orientation in colder than in warmer water temperatures. Moreover, an increase in activity with temperature is common in ectothermal animals.

The relevant component of the variable "weather condition" that the fish larvae reacted to was probably the light intensity (Probst and Eckmann 2009). With increasing light intensities, the deep open-water microhabitat was increasingly preferred. Examples of positive and negative phototaxis are also identified in many larval fish species (Colton and Hurst 2010; Yamada et al. 2009). Avoidance of high light intensities and thereby a reduction in the exposure to optically oriented predators is most likely also a main driver of the diel vertical migrations that many fish larvae perform (Probst and Eckmann 2009). The results of this study show that also during daylight, larval fish track changes in ambient light intensity leading to short-distance migrations on the microhabitat scale.

This study showed that the behavioural plasticity of larval fish is much greater than often assumed. With their ability to orient themselves along various environmental gradients and to adjust their microhabitat choice quickly, fish larvae have the potential to trade the costs and benefits of these environmental variables effectively. Applying these results to the context of navigation-induced hydrodynamic impacts, it is expected that the effects of navigational waves on larval fish will depend on the morphology of the shallow water habitats, especially on the presence or absence of short-distance evasion possibilities of the fish to wave-induced hydrodynamic impacts. Since inland shipping is propagated as an ecofriendly mode of transport in the EU (European Commission 2006) and other regions worldwide, a better understanding of the interaction of shipping and fish is most pertinent.

\section{Acknowledgements}

The study was funded by the LIFE financial instrument of the European Community (EU Life Project LIFE 06 NAT/D/ 00005) as well as by the research funding program LOEWE (Landes-Offensive zur Entwicklung Wissenschaftlich-ökonomischer Exzellenz) of Hesse's Ministry of Higher Education, Research and the Arts. We thank Hilmar Hofmann who lent an ADV to measure the current velocities in the wave mesocosm and we greatly appreciate his helpful discussions of wave physics. Robert B. O'Hara provided statistical consultancy. Martin Wolf offered technical support with the wave generator, and Wolfgang Nikolaus Probst, Daniela Harrer, and Michael Donner helped with the rearing of the fish larvae. We also thank two anonymous reviewers who provided comments that greatly improved this manuscript.

\section{References}

Arlinghaus, R., Engelhardt, C., Sukhodolov, A., and Wolter, C. 2002. Fish recruitment in a canal with intensive navigation: implications for ecosystem management. J. Fish Biol. 61(6): 13861402. doi:10.1111/j.1095 8649.2002.tb02484.x

Baltz, D.M., Vondracek, B., Brown, L.R., and Moyle, P.B. 1987. Influence of temperature on microhabitat choice by fishes in a California stream. Trans. Am. Fish. Soc. 116(1): 12 20. doi:10. 1577/1548 8659(1987)116<12:IOTOMC>2.0.CO;2.

Borcherding, J., and Magnhagen, C. 2008. Food abundance affects both morphology and behaviour of juvenile perch. Ecol. Freshwat. Fish, 17(2): 207 218. doi:10.1111/j.1600 0633.2007.00272.x.

Colton, A.R., and Hurst, T.P. 2010. Behavioral responses to light gradients, olfactory cues, and prey in larvae of two North Pacific gadids (Gadus macrocephalus and Theragra chalcogramma). Environ. Biol. Fishes, 88(1): 39 49. doi:10.1007/s10641 0109616 y.

Copp, G.H. 1992. Comparative microhabitat use of cyprinid larvae and juveniles in a lotic floodplain channel. Environ. Biol. Fishes, 33(1 2): 181 193. doi:10.1007/BF00002563.

Elso, J.I., and Greenberg, L.A. 2001. Habitat use, movements and survival of individual 0+ brown trout (Salmo trutta) during winter. Arch. für Hydrobiol. 152: 279295.

European Commission. 2006. Communication from the Commission on the promotion of inland waterway transport "NAIADES" An integrated European action programme for inland waterway transport, Office for Official Publications of the European Communities, Luxembourg.

Flore, L., Keckeis, H., and Schiemer, F. 2001. Feeding, energetic benefit and swimming capabilities of $0+$ nase (Chondrostoma nasus, L.) in flowing water: an integrative laboratory approach. Arch. für Hydrobiol. 135(Suppl.): 409424.

Frings, R.M., Kleinhans, M.G., and Vollmer, S. 2008. Discriminating between pore filling load and bed structure load: a new porosity based method, exemplified for the river Rhine. Sedimentology, 55(6): 1571 1593. doi:10.1111/j.1365 3091.2008.00958.x.

Gabel, F., Stoll, S., Fischer, P., Pusch, M.T., and Garcia, X. F. 2011 Waves affect predator prey interactions between fish and benthic invertebrates. Oecologia (Berl.), 165(1): 101 109. doi:10.1007/ s00442 0101841 8. PMID:21104276.

Gaudin, P. 2001. Habitat shifts in juvenile riverine fish. Arch. für Hydrobiol. 135(Suppl.): 395408.

Hofmann, H., Lorke, A., and Peeters, F. 2008. The relative importance of wind and ship waves in the littoral zone of a large lake. Limnol. Oceanogr. 53(1): 368 380. doi:10.4319/lo.2008.53. 1.0368 .

Holland, L.E. 1986. Effects of barge traffic on distribution and survival of ichthyoplankton and small fishes in the Upper Mississippi River. Trans. Am. Fish. Soc. 115(1): 162165.

Holland, L.E. 1987. Effect of brief navigation related dewaterings on fish eggs and larvae. N. Am. J. Fish. Manage. 7(1): 145147

Holland, L.E., and Sylvester, J.R. 1983. Distribution of larval fishes related to potential navigation impacts on the Upper Mississippi River, pool 7. Trans. Am. Fish. Soc. 112(2B): 293301.

Hurst, T.P., Cooper, D.W., Scheingross, J.S., Seale, E.M., Laurel, B.J, and Spencer, M.L. 2009. Effects of ontogeny, temperature, and light on vertical movements of larval Pacific cod (Gadus macrocephalus). Fish. Oceanogr. 18(5): 301 311. doi:10.1111/j. 1365 2419.2009.00512.x 
Kucera Hirzinger, V., Schludermann, E., Zornig, H., Weissenbacher, A., Schabuss, M., and Schiemer, F. 2009. Potential effects of navigation induced wave wash on the early life history stages of riverine fish. Aquat. Sci. 71(1): 94 102. doi:10.1007/s00027 008 81105.

Kundu, P.K., and Cohen, I.M. 2002. Fluid mechanics. Academic Press, London, UK.

Lamouroux, N., Olivier, J. M., Persat, H., Pouilly, M., Souchon, Y., and Statzner, B. 1999. Predicting community characteristics from habitat conditions: fluvial fish and hydraulics. Freshw. Biol. 42(2): 275 299. doi:10.1046/j.1365 2427.1999.444498.x.

Lienesch, P.W., and Matthews, W.J. 2000. Daily fish and zooplankton abundances in the littoral zone of Lake Texoma, Oklahoma Texas, in relation to abiotic variables. Environ. Biol. Fishes, 59(3): 271 283. doi:10.1023/A:1007688513523.

MacKenzie, B.R., and Kiørboe, T. 1995. Encounter rates and swimming behavior of pause travel and cruise larval fish predators in calm and turbulent laboratory environments. Limnol. Oceanogr. 40(7): 1278 1289. doi:10.4319/lo.1995.40.7.1278.

MacKenzie, B.R., Miller, T.J., Cyr, S., and Leggett, W.C. 1994. Evidence for a dome shaped relationship between turbulence and larval fish ingestion rates. Limnol. Oceanogr. 39(8): 17901799. doi: 10.4319/lo.1994.39.8.1790.

Mazumder, B.S., Bhowmik, N.G., and Soong, T.W. 1993. Turbulence in rivers due to navigation traffic. J. Hydraul. Eng. 119(5): 581 597. doi:10.1061/(ASCE)0733 9429(1993)119:5(581).

Montgomery, J.C., and Sutherland, K.B.W. 1997. Sensory develop ment of the Antarctic silverfish Pleuragramma antarcticum: a test for the ontogenetic shift hypothesis. Polar Biol. 18(2): 112115. doi:10.1007/s003000050165.

Probst, W.N., and Eckmann, R. 2009. The influence of light on the diel vertical migration of young of the year burbot Lota lota in Lake Constance. J. Fish Biol. 74(1): 150 166. doi:10.1111/j.1095 8649.2008.02120.x. PMID:20735530.

Probst, W.N., Stoll, S., Hofmann, H., Fischer, P., and Eckmann, R. 2009. Spawning site selection by Eurasian perch (Perca fluviatilis L.) in relation to temperature and wave exposure. Ecol. Freshwat. Fish, 18(1): 1 7. doi:10.1111/j.1600 0633.2008.00327.x.

Rothschild, B.J., and Osborn, T.R. 1988. Small scale turbulence and plankton contact rates. J. Plankton Res. 10(3): 465 474. doi:10. 1093/plankt/10.3.465.

Rupp, R. 1965. Shore spawning and survival of eggs of the American smelt. Trans. Am. Fish. Soc. 94(2): 160 168. doi:10.1577/1548 8659(1965)94[160:SASOEO]2.0.CO;2.

Sapède, D., Gompel, N., Dambly Chaudière, C., and Ghysen, A. 2002. Cell migration in the postembryonic development of the fish lateral line. Development, 129(3): 605 615. PMID:11830562.

Scheidegger, K.J., and Bain, M.B. 1995. Larval fish distribution and microhabitat use in free flowing and regulated rivers. Copeia, 1995(1): 125 135. doi:10.2307/1446807.

Stoll, S., and Beeck, P. 2011. Post release stranding rates of stocked allis shad (Alosa alosa) larvae exposed to surface wave action. J. Appl. Ichthyology, 27(Suppl. 3): 41 44. doi:10.1111/j.1439 0426. 2011.01879.x

Stoll, S., and Fischer, P. 2011. Three different patterns of how low intensity waves can affect the energy budget of littoral fish: a mesocosm study. Oecologia (Berl.), 165(3): 567 576. doi:10. 1007/s00442 0101793 z. PMID:20953799.

Stoll, S., Hofmann, H., and Fischer, P. 2010a. Effect of wave exposure dynamics on gut content mass and growth of young of the year fishes in the littoral zone of lakes. J. Fish Biol. 76(7): 1714 1728. doi: $10.1111 / \mathrm{j} .1095$ 8649.2010.02611.x. PMID: 20557626.

Stoll, S., Probst, W.N., Eckmann, R., and Fischer, P. 2010b. A mesocosm experiment investigating the effects of substratum quality and wave exposure on the survival of fish eggs. Aquat. Sci. 72(4): 509 517. doi:10.1007/s00027010 01529.

Utne Palm, A.C. 2004. Effects of larvae ontogeny, turbidity, and turbulence on prey attack rate and swimming activity of Atlantic herring larvae. J. Exp. Mar. Biol. Ecol. 310(2): 147 161. doi:10. 1016/j.jembe.2004.04.005

Utne Palm, A.C., and Stiansen, J.E. 2002. Effect of larval ontogeny, turbulence and light on prey attack rate and swimming activity in herring larvae. J. Exp. Mar. Biol. Ecol. 268(2): 147 170. doi:10. 1016/S0022 0981(01)003835.

Véron, V., Jatteau, P., and Bardonnet, A. 2003. First results on the behavior of young stages of allis shad (Alosa alosa). In Biodiversity, status and conservation of the world's shads. Symposium 35, Bethesda, Md. pp. 241251.

Watt Pringle, P., and Strydom, N.A. 2003. Habitat use by larval fishes in a temperate South African surf zone. Estuar. Coast. Shelf Sci. 58(4): 765 774. doi:10.1016/S0272 7714(03)00183 5.

Webb, P.W. 2002. Control of posture, depth and swimming trajectories of fishes. Int. Comp. Biol. 42(1): 94 101. doi:10. 1093/icb/42.1.94.

Wieser, W. 1985. Developmental and metabolic constraints of the scope for activity in young rainbow trout. J. Exp. Biol. 118: 133 142.

Wolter, C., and Arlinghaus, R. 2003. Navigation impacts on freshwater fish assemblages: the ecological relevance of swim ming performance. Rev. Fish Biol. Fish. 13(1): 63 89. doi:10. 1023/A:1026350223459.

Wolter, C., Arlinghaus, R., Sukhodolov, A., and Engelhardt, C. 2004 A model of navigation induced currents in inland waterways and implications for juvenile fish displacement. Environ. Manage. 34(5): 656 668. doi:10.1007/s00267 0040201 z. PMID:15549651.

Yamada, Y., Okamura, A., Mikawa, N., Utoh, T., Horie, N., Tanaka, S., Miller, M.J., and Tsukamoto, K. 2009. Ontogenetic changes in phototactic behavior during metamorphosis of artificially reared Japanese eel Anguilla japonica larvae. Mar. Ecol. Prog. Ser. 379: 241 251. doi: 10.3354/meps07912. 